\title{
SUPPRESSING EFFECT OF X-333 ON THE TOXICITY OF AFLATOXIN ANI PESTICIDES IN THE LAYING HEN
}

\author{
V. de ANDRES et J. de ANDRES \\ Station de Recherches avicoles, \\ Centre de Recherches de Tours, I. N.R. A., \\ Nouzilly, 37380 Monnaie
}

In order to decrease the toxic effects of aflatoxin and pesticides in the laying hen, a food additive has been tested on 84 hens raised in individual cages and distributed into 4 equal groups. With this additive, the laying rate only decreased $40 \mathrm{p}$. Ioo compared to $90 \mathrm{p}$. Ioo without additive. Morever, the blood GOT and cholesterol increase was reduced. Some complementary trials are in progress to complete our observations.

\section{EFFECT OF LYSINE DEFICIENCY DURING THE GliOWING PERIOD WITH OR WITHOUT DEFICIENCY DURING THE LAYING PERIOD ON THE PERFOHMANCES OF THE LAYING HEN}

\author{
M. LARBIER et J. GUILLAUME \\ Station de Recherches avicoles, \\ Centre de Recherches de Tours, I. N. R. A., \\ Nouzilly, 37380 Monnaie
}

An experiment was carried out on izo pullets to determine the effects of a lysine deficiency during the growing period followed or not by a lysine deficiency during the laying period. From o to $\mathbf{1} 7$ weeks, the pullets were fed ad libitum either a complete diet (T) or a diet deficient in lysine (L). Then each group was split into 2 batches of hens reared in cages and fed a complete laying diet (N) or a lysine deficient laying diet (C).

Lysine deficiency during the growing period ( $\mathrm{LN}$ and $\mathrm{LC}$ ) reduced live weight, feed intake and feed efficiency. It also delayed sexual maturity, but did not modify the laying performances, except egg weight. Lysine deficiency during the laying period (TC and LC) sharply decreased weight gain, laying rate and egg weight. But this latter reduction was much more pronounced in LC birds than in TC birds $(2.5 \mathrm{~g}$ instead of $0.4 \mathrm{~g}$ significant interaction). Therefore an early deficiency in lysine makes the pullets more susceptible to a later lysine deficiency, at least as far as egg weight is concerned. 